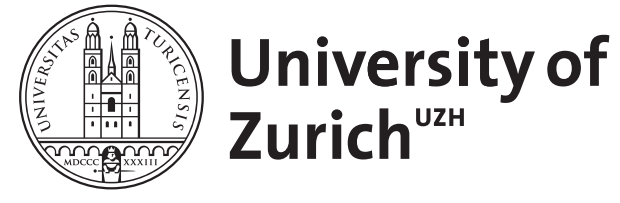

\title{
Avant-propos de Daniel Thürer
}

Thürer, Daniel

\begin{abstract}
Il y a cinquante ans... le 10 décembre 1948, l'Assemblée générale des Nations Unies adoptait solennellement la Déclaration universelle des droits de l'homme. Cet événement a constitué un tournant dans le développement du droit international. Dès lors, il a été considéré que l'être humain, dont les droits avaient été fixés au cours de la longue évolution de l'histoire constitutionnelle, était au centre du système juridique international.
\end{abstract}

DOI: https://doi.org/10.1017/s0035336100055982

Posted at the Zurich Open Repository and Archive, University of Zurich ZORA URL: https://doi.org/10.5167/uzh-155333

Journal Article

Published Version

Originally published at:

Thürer, Daniel (1998). Avant-propos de Daniel Thürer. International Review of the Red Cross, 80(831):434435.

DOI: https://doi.org/10.1017/s0035336100055982 


\section{Avant-propos de Daniel Thürer}

Il y a cinquante ans... le 10 décembre 1948, l'Assemblée générale des Nations Unies adoptait solennellement la Déclaration universelle des droits de l'homme. Cet événement a constitué un tournant dans le développement du droit international. Dès lors, il a été considéré que l'être humain, dont les droits avaient été fixés au cours de la longue évolution de l'histoire constitutionnelle, était au centre du système juridique international.

Il y a trente ans... la Conférence internationale des droits de l'homme, tenue à Téhéran en 1968 pour commémorer la Déclaration universelle, adoptait une résolution sur le «respect des droits de l'homme en période de conflit armé ». En mettant en lumière les règles et les principes du droit international humanitaire, les Nations Unies montraient clairement qu'il existait une doctrine bien antérieure à leur propre droit des droits de l'homme. De fait, Jean Pictet a fait observer à juste titre que, dès 1864, l'adoption de la toute première Convention de Genève, ou Convention de la "Croix-Rouge», avait marqué le début d'une ère qui donnait la primauté à l'individu et aux principes d'humanité.

Aujourd'hui... nous constatons que les deux traditions - le droit des droits de l'homme et le droit des conflits armés - se rapprochent de plus en plus:

- dans la plupart des conflits armés contemporains, les deux ensembles de règles s'appliquent, parfois de façon complémentaire, mais le plus souvent en parallèle ;

- de plus en plus, on reconnaît que le droit international humanitaire doit être interprété à la lumière du droit des droits de l'homme, et vice versa ;

- un nombre croissant de juristes internationaux considèrent que les deux systèmes de règles s'étayent mutuellement ; 
- bien que le droit international ait établi différents mécanismes en vue de la mise en cuvre du droit international humanitaire et de celle du droit des droits de l'homme, les deux ensembles de règles sont, de plus en plus souvent, appliqués ou invoqués de façon interchangeable.

Nous allons donc vivre une fascinante évolution: le droit international des droits de l'homme et le droit international humanitaire, tout en demeurant distincts, se rapprochent. Le thème de ce numéro de la Revue internationale de la Croix-Rouge est donc indéniablement aussi pertinent qu'opportun.

Daniel Thürer

Professeur, Université de Zurich

Membre du CICR 